\title{
Adult acquired cytomegalovirus infection with gastric and duodenal ulceration
}

\author{
R C SPILlER, D LOVELL, AND D B A SILK \\ From the Departments of Gastroenterology and Nutrition, and Department of Histopathology, Central \\ Middlesex Hospital, London
}

SUMMARY Recent reports of cytomegalovirus associated colonic and oesophageal ulceration in immunosuppressed patients infected with the human immunodeficiency virus, ${ }^{1-3}$ have focussed attention on the possibility that viral infections may in some cases be the initial insult which leads in susceptible subjects to gastrointestinal ulceration. In this case report we describe how systemic primary infection with the cytomegalovirus was associated with the development of multiple gastric and duodenal erosions.

\section{Case report}

This 44 year old Spanish domestic worker was admitted to Central Middlesex Hospital with a four week history of malaise and nocturnal sweating and a two week history of postprandial vomiting and epigastric pain, partially relieved by antacids. Four years previously she had suffered from a duodenal ulcer which was shown endoscopically to heal after two months' treatment with ranitidine $150 \mathrm{mg}$ twice daily. About that time she stopped smoking and had been asymptomatic and off treatment since then. Apart from prochloperazine for vomiting, she had taken no drugs or alcohol in the previous few months. Physical examination revealed epigastric tenderness and a firm splenic edge felt four fingers' breadth below the left costal margin. There was no peripheral lymphadenopathy and the remainder of the examination including fundoscopy was normal.

Investigations revealed a haemoglobin of $14 \cdot 3 \mathrm{~g} / \mathrm{dl}$, white cell count was $8.0 \times 10^{\%} / 1,31 \%$ polymorphs, $59 \%$ lymphoctyes with many atypical forms suggestive of a viral infection. Monospot test for infectious mononucleosis was negative and urea, electrolytes, blood glucose and amylase were all normal. Liver

Address for correspondence: Dr R C Spiller. Department of Therapeutics. University Hospital. Queens Medical (entre. Nottingham.

Received for publication 29 February 1988. function tests were abnormal with a slight rise in serum enzymes, ALT 91 and AST 44 IU/l (normal $<35$ ), and raised alkaline phosphatase 549 IU/l (normal $<280$ ). Bilirubin, albumin, globulin, and prothrombin time were all normal. Autoantibody screen and VDRL test for treponemal infection was negative and serum gastrin was $<6 \mathrm{pmol} / \mathrm{l}$. Ultrasound confirmed uniform splenomegaly with a normal liver, gall bladder, and pancreas. There was no hilar lymphadenopathy on chest $x$-ray and microscopy of the urine was normal.

At endoscopy the antrum and duodenum were grossly inflamed with multiple small $(2 \mathrm{~mm}$ diameter $)$ shallow ulcers extending from the antrum to the second part of the duodenum associated with generalised mucosal reddening and oedema. Superficial biopsies of the edge of the antral lesions showed a florid gastritis with increased inflammatory cells and polymorph infiltration, while the duodenal biopsies showed severe duodenitis with inflammatory infiltration in both the lamina propria and glandular epithelium.

Further investigation of the cause of her splenomegaly included liver biopsy and bone marrow aspirate. The liver biopsy showed a variable degree of round cell infiltration in the portal tracts, with some mononuclear cells in the liver sinusoids but preservation of liver architecture. Bone marrow aspirate showed a small population of atypical, large, 
reactive lymphocytes compatible with a recent viral infection.

Subsequently obtained assays for $\operatorname{IgM}$ and $\operatorname{IgG}$ antibodies to cytomegalovirus were strongly positive using an ELISA test at a screening dilution of 1 in 300. Two months later IgG antibodies were still strongly positive while IgM antibodies were equivocal indicating a significant fall in IgM antibodies compatible with a recent CMV infection. Other serological tests included a negative monospot test and negative assays for hepatitis B surface antigen, anti-core antibody and hepatitis A IgM antibody though hepatitis A IgG was positive indicating previous infection with hepatitis A virus.

After restarting ranitidine the patient's vomiting ceased and after a further few days the patient was discharged for outpatient follow up. Over the next four months the splenomegaly resolved and the patient returned to normal health no longer requiring ranitidine. Atypical lymphocytes persisted for a further two months. The patient was then discharged well but reattended 12 months later complaining of visual impairment which was found to be caused by extensive inactive choroidoretinitis with pale scars and patchy pigmentation around the right macula and left disc.

\section{Discussion}

We believe that our patient developed multiple gastric and duodenal ulcers as a result of adult acquired cytomegalovirus infection, an illness characterised by splenomegaly, mild hepatitis, and choriodoretinitis as well as the upper gastrointestinal lesions.

Cytomegalovirus is a ubiquitous DNA virus of the herpes family which infects $60 \%$ of the United Kingdom population by the age of 50 years. ${ }^{4}$ Once it enters the body the virus remains latent but is capable of being reactivated if immune defences are impaired. The majority of infections are asymptomatic but occasionally young adults present, as our patient did, with an 'infectious mononucleosis' type illness with fever, malaise and atypical lymphocytosis. Of nine such patients reported by Jordan $e t$ $a l^{5}$ eight had fever, three splenomegaly and three anorexia. Abdominal pain as seen in our patient was noted in two but they were not endoscoped so we do not know whether they also had upper gastrointestinal ulceration. All nine had atypical lymphocytosis and six, like our patient, had modest rises in serum ALT.

The majority of gastrointestinal ulcers which have previously been reported in association with CMV have been associated with immunosuppression. Thus Levine reported four cases of gastrointestinal ulcers with CMV in the granulation tissue at the base of the ulcers, three of the patients being on high dose steroids." Likewise Henderson found immunosuppression in six of eight patients in whom necropsy revealed CMV in the granulation tissue of gastrointestinal ulcers.' More recently CMV has been detected in oesophageal " and colonic ulcers' in patients with AIDS. Although we salw no CMV inclusion bodies in our biopsy material we did attempt to show CMV antigen using an immunofluorescent technique but without success. This was perhaps not unexpected as while our samples were very superficial, the virus has usually been shown in surgical specimens deep in the granulation tissue of gastrointestinal ulcers. Furthermore if CMV is to be detected such studies should be done on fresh biopsy material which was of course not possible in our case, as the diagnosis was not suspected until sometime after the endoscopy.

Our case is unusual in that the patient had no features to suggest immunodeficiency and appears to have had a primary infection with generalised viraemia affecting liver, lymphatic tissue, and retina as well as the upper gastrointestinal tract in which it appears to have caused the development of frank ulceration. The fact that there were multiple ulcers supports our contention that these were not preexisting ulcers but rather the result of viral dissemination. Multiple gastric ulcers are distinctly unusual and are rarely seen together with duodenal ulcers unless they are stress, or drug induced or part of the Zollinger Ellisson syndrome. The only drug that our patient had taken was prochlorperazine, which has not been associated with gastric ulceration, furthermore her symptoms antedated drug ingestion making it unlikely that this caused her ulcers. Normal plasma gastrin concentrations together with lack of recurrence over the subsequent two years effectively excludes the Zollinger Ellisson syndrome.

The only previous report in which CMV infection clearly preceded the development of mucosal ulceration is that of Foucar ${ }^{x}$ who showed CMV in the urine of renal transplant patients which preceded the development of severe and ultimately fatal colonic ulceration caused by CMV infection by days or, in some cases, months.

As the annual seroconversion rate for $\mathrm{CMV}$ is approximately $1 \%$, it is clear that most cases of CMV go clinically unrecognised. What proportion of these manifest themselves as an attack of epigastric pain and vomiting settling with antacids is unclear, but even if this were only one in 10 this would still mean 60000 cases per annum in the United Kingdom.

Until recently such considerations have been of largely academic interest, however it seems likely that with the recent stimulus to the development of effective antiviral therapy provided by the AIDS 
epidemic it will soon be possible to inhibit CMV replication.' This gives new urgency to the establishment of the role of CMV in gastrointestinal ulceration. In the present case the acute mucosal lesions appear to have been short lived but the possibility exists that gastric ulceration associated with the use of steroids, as in for example, rheumatoid arthritis, could be exacerbated by reactivation of latent CMV which would be expected to be present in nearly half the patients.

\section{References}

1 Weber JN, Thom S, Barrison I, et al. Cytomegalovirus colitis and oesophageal ulceration in the context of AIDS: clinical manifestations and preliminary report of treatment with Foscarnet (phosphonoformate). Gut 1987; 28: 482-7.

2 Meiselman MS, Cello JP, Margaretten W. Cytomegalo- virus colitis. Report of the clinical, endoscopic, and pathologic findings in two patients with the acquired immune deficiency syndrome. Gastroenterology 1985; 88: $171-5$.

3 St Onge G, Bezahler GH. Giant esophageal ulcer associated with cytomegalovirus. Gastroenterology 1982; 83: $127-30$.

4 Starr SE. Cytomegalovirus. Pediatr Clinics N Am 1979): 26: $283-93$.

5 Jordan MC, Rousseau WE. Stewart JA, Noble GR, Chin TDY. Spontaneous cytomegalovirus mononucleosisclinical and laboratory observations in nine cases. Ann Intern Med 1973; 79: 153-60.

6 Levine RS, Warner NE, Johnson CF. Cytomegalic inclusion disease in the gastrointestinal tract of adults. Ann Surg 1964; 159: 37-48.

7 Henson D. Cytomegalovirus inclusion bodies in the gastrointestinal tract. Arch Pathol 1972; 93: 477-82.

8 Foucar E, Mukai K, Foucar K, Sutherland DER, Van Buren CT. Colon ulceration in lethal cytomegalovirus infection. Am J Clin Pathol 1981; 76: 788-801. 